\title{
Facility Requirement Analysis of an UHV Transformer's Short-circuit Test
}

\author{
Zhanfeng Zheng ${ }^{1}$, Xike $\mathrm{Wu}^{1}$, Shen Hong ${ }^{1}$, Guan $\mathrm{Hu}^{1}$, Leyi Ge ${ }^{2}$, Ji Liư ${ }^{1}$, Ping Yi ${ }^{1}$ \\ and Zhengping Ding ${ }^{3}$ \\ ${ }^{1}$ R\&D Center of Smart Electrification Equipment Business Unit, NARI Group Corporation, SGCC, \\ Nanjing, 211106, China \\ ${ }^{2}$ Beijing Electricity Research Huayuan Electric Technology Co., NARI Group Corporation, SGCC, \\ Beijing, 102200, China \\ ${ }^{3}$ China Electric Power Equipment and Technology Co., SGCC, Beijing, 100052, China
}

Keywords: ultra-high voltage, transformer, short-circuit test, short circuit generator, IEC 60076.5

\begin{abstract}
As the global energy problem becomes more and more severe, the ultra-high voltage (UHV) AC transmission technology will get a large number of applications. The UHV transformer, as one of the important equipments of the transmission system, its quality and reliability is directly related to the safe and stable operation of power system. At present, the normal performance of the UHV transformer is available by test method, except the ability to withstand short circuit need have the aid of calculation and simulation. Based on transformer short-circuit test requirements, the UHV transformer's maximum test ability of Changzhou Inspection \& Testing Center for Electrical Equipment and the facility requirement of the commercial UHV transformer's short-circuit test are analyzed respectively in this paper.
\end{abstract}

\section{Introduction}

With the increase of energy demand, the scale of power system is more and more large. Because of large transport capacity, long transmission distance, low line loss, less occupation of land etc, the ultra-high voltage (UHV) AC transmission technology gains more favor in the field of large capacity power transmission over a long distance [1]. In China, there have been two 1000kV AC transmission lines into commercial operation, and there are three similar lines under construction [2, 3]. Predictably, the more severe situation of the global energy problem, the larger number of applications of the UHV AC transmission technology will be got. The UHV transformer, as one of the important equipments of the transmission system, its quality and reliability is directly related to the safe and stable operation of power system [4]. At present, the normal performance of the UHV transformer is available by test method, except the ability to withstand short circuit need have the aid of calculation and simulation $[5,6]$. Therefore, Based on transformer short-circuit test requirements, the UHV transformer's maximum test ability of Changzhou Inspection \& Testing Center for Electrical Equipment and the facility requirement of the commercial UHV transformer's short-circuit test are analyzed respectively in this paper.

\section{Requirement of the Transformer's Short-circuit Test}

For the UHV transformer short-circuit test, the test ability mainly decided by two factors:

One is the total impedance of test loop, namely under the test voltage, whether it has the output current, which is the 《IEC 60076.5 Power transformers Part 5: the Ability to withstand short circuit current 》 required, the other is the working ability of the test equipment itself, to test of the $1000 \mathrm{kV}$ transformer, it need to increase the working voltage and the insulation level of the testing transformer.

According to IEC60076.5 rules, the short-circuit test of single-phase transformer satisfies the following equation [7]: 


$$
\begin{aligned}
& Z_{s}=\frac{U_{s}^{2}}{S}=\frac{U_{s}}{I_{s}} \\
& Z_{t}=\frac{U_{k} \cdot U_{r}^{2}}{S_{r}} \\
& I=\frac{U_{r}}{Z_{s}+Z_{t}} \\
& I_{t}=\frac{U_{2}}{Z_{r}+Z_{t}} \\
& I_{t} \geq 0.9 \cdot I
\end{aligned}
$$

Where, $\mathrm{S}$ is the apparent short circuit capacity of the system, Us is the system nominal voltage, Is is the short circuit current of the system, $\mathrm{Zs}$ is the short circuit impedance of the system , $\mathrm{Sr}$ is the rated capacity of the test object, $U r$ is the rated voltage of the test winding, $U_{k}$ is the short circuit impedance percentage of the test of winding, $\mathrm{Zt}$ is the test winding's short-circuit impedance of the sample transformer, $\mathrm{I}$ is the short circuit current value of the test winding under the rated capacity , $\mathrm{U}_{2}$ is the test voltage which is added to the winding, $\mathrm{Zr}$ is the system short-circuit impedance which converts to the side of the $\mathrm{U}_{2}$, It is the winding short circuit current value which $\mathrm{U}_{2}$ under test voltage.

The main technical parameters of $1000 \mathrm{kV}$ transformer are as follows: the nominal voltage of high voltage winding is $1050 / \sqrt{3} \mathrm{kV}$, the short circuit impedance percentage of high-medium voltage winding is $18 \%$, the $1000 \mathrm{kV}$ level system short circuit current is $63 \mathrm{kA}[8,9]$. Therefore, put the above parameters in formula (1) (3), can get the following equation:

$$
\begin{aligned}
& Z_{s}=\frac{1000 \cdot 10^{3}}{\sqrt{3} \cdot 63 \cdot 10^{3}}=9.2 \Omega \\
& Z_{t}=\frac{0.18 \cdot\left(\frac{1050}{\sqrt{3}} \cdot 10^{3}\right)^{2}}{S_{r}}=\frac{66154}{S_{r}} \cdot 10^{6} \\
& I=\frac{\frac{1050}{\sqrt{3}} \cdot 10^{3}}{9.2+Z_{t}}=\frac{606236}{9.2+Z_{t}}
\end{aligned}
$$

\section{Analysis of the Test Facility Requirement}

\section{Capacity of the UHV Transformer}

Through research, there are three capacity specifications for the UHV power system, which is shown in the tab. 1 [10]. And it shows that the UHV transformer minimum capacity specification is 400 MVA. 
Tab. 1 The UHV transformer specification

\begin{tabular}{|c|c|c|c|}
\hline No. & Specification & Type & Application Situation \\
\hline 1 & $\begin{array}{c}1000 \mathrm{MVA} / 1000 \mathrm{kV} \\
\text { /single-phase }\end{array}$ & line transformer & $\begin{array}{c}\text { used in the UHV AC } \\
\text { transmission line }\end{array}$ \\
\hline 2 & $\begin{array}{c}1500 \mathrm{MVA} / 1000 \mathrm{kV} \\
\text { /single-phase }\end{array}$ & line transformer & $\begin{array}{c}\text { successfully developed but } \\
\text { not usded in application }\end{array}$ \\
\hline 3 & $\begin{array}{c}400 \mathrm{MVA} / 1000 \mathrm{kV} \\
\text { /single-phase }\end{array}$ & $\begin{array}{c}\text { generator } \\
\text { transformer }\end{array}$ & $\begin{array}{c}\text { used in the Huainan Pingwei } \\
\text { power plant }\end{array}$ \\
\hline
\end{tabular}

\section{Analysis of the CITCEE's Test Ability}

As shown in fig. 1, the transformer's short-circuit test system of Changzhou Inspection \& Testing Center for Electrical Equipment (CITCEE) include: 2*6500 MVA short-circuit generator and 6*single phase short-circuit transformer.

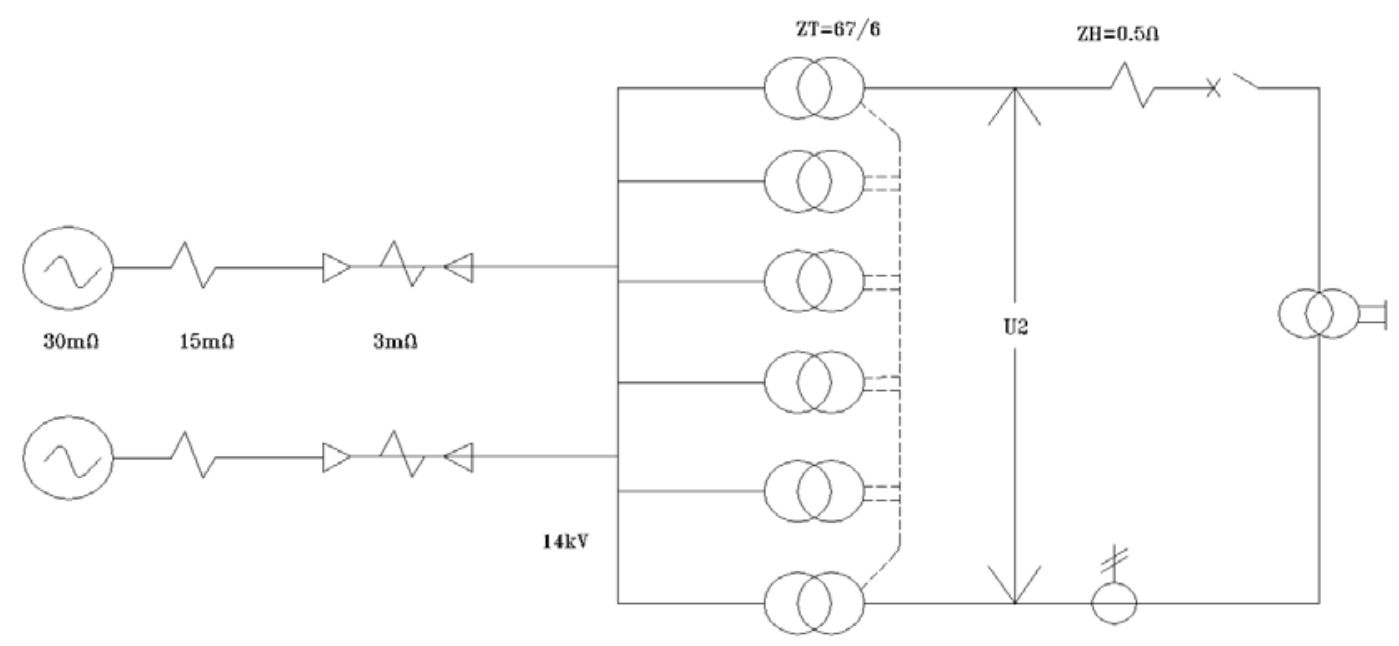

Fig. 1 The schematic diagram of the transformer's short-circuit test system in the CITCEE

The sub transient reactance $\mathrm{X}_{\mathrm{d}}$ "' of the generator is $30 \mathrm{~m} \Omega$, rated voltage is $14 \mathrm{kV}$, the short-circuit transformer, variable ratio is $14 \mathrm{kV} / 2 * 136 \mathrm{kV}$, the impedance of the side of $14 \mathrm{kV}$ is $67 \mathrm{~m} \Omega$; circuit impedance of high voltage side is $0.5 \mathrm{~m} \Omega$, which can convert to system impedance about the side of the high voltage:

$$
Z_{r}=\left\{\frac{[(30+15) \cdot 2+3] \cdot \frac{1}{2}+\frac{67}{6}}{10^{3}}\right\} \cdot\left(\frac{U_{2}}{14}\right)^{2}+0.5 \cdot 2=0.0577 \cdot\left(\frac{U_{2}}{14}\right)^{2}+1
$$

Six sets of high voltage short-circuit transformer through vary series and parallel way can get test voltage $\mathrm{U}_{2}$ is $680 \mathrm{kV}, 816 \mathrm{kV}, 952 \mathrm{kV}$ and $1088 \mathrm{kV}$.

(1) Put $U_{2}$, formula (4), formula (6)-(9) into formula(5),we can get a preliminary scheme of the maximum capacity of the UHV transformer short-circuit test, as is shown in table 2. It shows that the UHV transformer test capacity of CITCEE can only reach 200 MVA, it does not meet the requirements. 


\section{Analysis of Minimum Test System Requirement}

The calculation in the previous section shows that: the CITCEE is difficult to meet the demands of the commercial UHV transformer's short circuit test, mainly reflected in larger system impedance, the essence of which is test capacity is not enough. Therefore, it is necessary to reduce the high voltage transformer short-circuit impedance, improve its capacity; also need to increase the number of the paralleled short-circuit generator and high voltage short-circuit transformer.

Tab. 2 Short-circuit Test Ability of the CITCEE

\begin{tabular}{|c|c|c|c|c|}
\hline No. & $\begin{array}{c}\text { Testing } \\
\text { voltage } \\
(\mathrm{kV})\end{array}$ & $\begin{array}{c}\text { ratio of test voltage } \\
\text { and winding voltage }\end{array}$ & $\begin{array}{c}\text { system } \\
\text { impedance } \\
(\Omega)\end{array}$ & $\begin{array}{c}\text { The maximum } \\
\text { test ability } \\
\text { (MVA) }\end{array}$ \\
\hline 1 & 680 & 1.12 & 137 & 131 \\
\hline 2 & 816 & 1.35 & 197 & 179 \\
\hline 3 & 952 & 1.57 & 268 & 194 \\
\hline 4 & 1088 & 1.80 & 349 & 200 \\
\hline
\end{tabular}

First of all, to promote high voltage short-circuit transformer parameters: the side of $14 \mathrm{kV}$ impedance reduced to $40 \mathrm{~m} \Omega$, insulation level increase from $330 \mathrm{kV}$ to $750 \mathrm{kV}$.

Suppose that number of short-circuit generator is $\mathrm{m}$, number of paralleled high voltage short-circuit transformer is $\mathrm{n}$, internal impedance of the test system can be obtained:

$$
Z_{r}^{\prime}=\left\{\frac{[(30+15) \cdot 2+3] \cdot \frac{1}{m}+\frac{40}{n}}{10^{3}}\right\} \cdot\left(\frac{U_{2}}{14}\right)^{2}+0.5 \cdot 2
$$

For $\mathrm{U}_{2}$ is $816 \mathrm{kV}$, can get $\mathrm{U}_{2}$ ' is:

$$
U_{2}^{\prime}=U_{2} \cdot \frac{15}{14}
$$

Then can get:

$$
\begin{aligned}
& I_{t}^{\prime}=\frac{U_{2}^{\prime}}{Z_{r}^{\prime}+Z_{t}} \\
& I_{t}^{\prime} \geq 0.9 \cdot I
\end{aligned}
$$

Put formula (6) (8) and formula (10) (12) into formula (13), can get:

$$
\frac{93}{m}+\frac{40}{n} \leq \frac{11731}{S_{r} \cdot 10^{-6}}+4.045
$$

The physical meaning: when the sample transformer whose capacity is $\mathrm{Sr}$ is tested in $\mathrm{U}_{2}$ voltage, the testing system must satisfy the expression (14) in order to meet the standard requirements.

(1) 400MVA/1000kV Transformer

Put $\mathrm{Sr}=400 \mathrm{MVA}$ into formula (14), we can get $\mathrm{m}=4, \mathrm{n}=6$. The minimum system that meets the test requirements is: 4 sets of short-circuit generator and 6 sets of high voltage short-circuit transformer. 
(2) 1000MVA/1000kV Transformer

Put $\mathrm{Sr}=1000 \mathrm{MVA}$ into formula (14), we can get $m=8, n=12$. The minimum system that meets the test requirements is: 8 sets of short-circuit generator and 12 sets of high voltage short-circuit transformer.

(3) 1500MVA/1000kV Transformer

Put $S r=1500 M V A$ into formula (14), we can get $m=10, n=16$. The minimum system that meets the test requirements is: 10 sets of short-circuit generator and 16 sets of high voltage short-circuit transformer.

On the basis of existing equipments, we need to add new equipments and investments, such as tab. 3. The unit of investment is ten thousand Yuan.

Tab. 3 New equipment requirements for the commercial UHV transformer short-circuit test

\begin{tabular}{|c|c|c|c|c|c|c|c|}
\hline \multirow{3}{*}{ No. } & \multirow{3}{*}{ list } & \multicolumn{6}{|c|}{$1000 \mathrm{kV}$} \\
\hline & & \multicolumn{2}{|c|}{ 400MVA } & \multicolumn{2}{|c|}{ 1000MVA } & \multicolumn{2}{|c|}{ 1500MVA } \\
\hline & & num. & cost & num. & cost & num. & cost \\
\hline 1 & $\begin{array}{l}\text { 6500MVA generator } \\
\text { unit }\end{array}$ & 2 & 24000 & 6 & 72000 & 8 & 96000 \\
\hline 2 & $\begin{array}{l}\text { circuit breakers, reactors } \\
\text { etc. in generator loop }\end{array}$ & 2 & 10000 & 6 & 30000 & 8 & 40000 \\
\hline 3 & $\begin{array}{l}\text { transformer( } 40 \mathrm{~m} \Omega \\
750 \mathrm{kV} \text { dielectric level) }\end{array}$ & 0 & 0 & 6 & 16200 & 10 & 27000 \\
\hline 4 & $\begin{array}{l}\text { original proposal } \\
\text { transformer upgrade } \\
\text { costs (Each impedance } \\
\text { down to } 40 \mathrm{~m} \Omega \text { from } \\
67 \mathrm{~m} \Omega \text { in } 14 \mathrm{kV} \text { side, } \\
\text { dielectric level updated } \\
\text { from } 330 \mathrm{kV} \text { to } 750 \mathrm{kV} \\
\text { Level) }\end{array}$ & 6 & 9000 & 6 & 9000 & 6 & 9000 \\
\hline 5 & $\begin{array}{l}\text { 1100kV SF6 } \\
\text { phase-controlled closing } \\
\text { switch }\end{array}$ & 1 & 2000 & 1 & 3000 & 1 & 3000 \\
\hline 6 & $\begin{array}{l}\text { 1100kV loop current } \\
\text { transformers, voltage } \\
\text { transformers, surge } \\
\text { arresters, architecture, } \\
\text { etc. }\end{array}$ & 1 & 1000 & 1 & 3000 & 1 & 3000 \\
\hline 7 & $\begin{array}{l}\text { 2x252kV insulating } \\
\text { platform }\end{array}$ & 1 & 1000 & 1 & 1500 & 1 & 1500 \\
\hline 8 & $\begin{array}{l}\text { updating measuring } \\
\text { equipment }\end{array}$ & 1 & 500 & 1 & 800 & 1 & 800 \\
\hline 9 & sub total & \multicolumn{2}{|c|}{47500} & \multicolumn{2}{|c|}{135500} & \multicolumn{2}{|c|}{180300} \\
\hline 10 & $\begin{array}{l}\text { transportation cost } \\
(5 \%)\end{array}$ & \multicolumn{2}{|c|}{2375} & \multicolumn{2}{|c|}{6775} & \multicolumn{2}{|c|}{9015} \\
\hline 11 & $\begin{array}{l}\text { installation cost } \\
(10 \%)\end{array}$ & \multicolumn{2}{|c|}{4750} & \multicolumn{2}{|c|}{13550} & \multicolumn{2}{|c|}{18030} \\
\hline & Total & \multicolumn{2}{|c|}{64625} & \multicolumn{2}{|c|}{155825} & \multicolumn{2}{|c|}{207345} \\
\hline
\end{tabular}




\section{Conclusion}

Based on the above analysis, we can get the following conclusion:

(1)Even if we don't consider the insulation level of the equipments, the UHV transformers' short-circuit test capacity of the CITCEE can only reach 200 MVA. It does not meet the practical requirements.

(2)Meeting the requirements of the commercial UHV transformers' short circuit test, the CITCEE need increase a big amount investment to buy the short-circuit generator and the short-circuit transformer.

\section{References}

[1] Z. Y. Liu, Ultra-high voltage AC \& DC grid, China Electric Power Press, Beijing, 2013.

[2] Z. Y. Liu, Innovation of UHVAC Transmission Technology in China, Power System Technology. 3(2013)566-574.

[3] Y. B. Shu, W. L. Zhang, Research of key technologies for UHV transmission, Proceedings of the CSEE. 31(2007)1-6.

[4] R.P.P. SMEETS, L.H. TE PASKE, P.P. LEUFKENS, et al, Thirteen years test experience with short-circuit withstand capability of large power transformers, 6th Southern Africa Regional Conf. CIGRE, Cape Town, South Africa, 2009, pp.1-7.

[5] Yury G. Shakaryan1, Yury A. Dementyev, Alexander Yu. Khrennikov, Short current Testing Laboratories, Short-Circuit Performance of Power Transformers, Transformer Testing Experience, International Journal of Automation and Control Engineering. 2(2013)120-127.

[6] R. K. Tiwari, S. K. Gupta, R. K. Singh, et al, Critical technical aspects during design, manufacturing and testing of India's first $1200 \mathrm{kV}$ UHVAC transformer. 12(2012)19-24.

[7] IEC 60076.5: Power transformers - Ability to withstand short circuit, 2012.

[8] Z. R. Wu, B. J. Chen, X. Li, Structure Selection and Test of $1000 \mathrm{kV}$ Transformer for UHVAC Test Base of SGCC, High Voltage Technology. 11(2008)10-14.

[9] G. F. Li, X. N. Wang, P. Li, et al, Insulation Level and Test Technology of 1000kV Power Transformers, Power System Technology. 3(2008)1-6.

[10] L. Guan, G. F. Li, B. Li, et al, Manufacture Technology and Development of UHV Power Transformer in China, Transformer. 8(2014)28-33. 